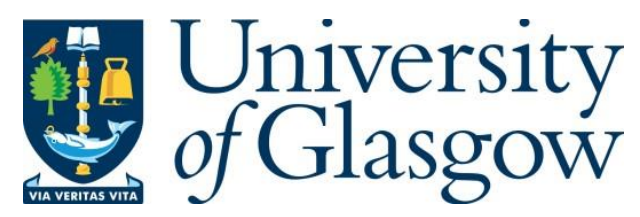

Pickering, L. and Greenwood, S. (2019) New for who?: Novelty and continuity in drugrelated practices of people who use new psychoactive substances. Contemporary Drug Problems, 46(4), pp. 323-344.

There may be differences between this version and the published version. You are advised to consult the publisher's version if you wish to cite from it.

http://eprints.gla.ac.uk/199797/

Deposited on: 11 October 2019

Enlighten - Research publications by members of the University of Glasgow http://eprints.gla.ac.uk 


\title{
New for Who? Novelty and Continuity in Drug-Related Practices of People who Use New Psychoactive Substances
}

\begin{abstract}
New (or Novel) Psychoactive Substances or NPS are so-called because they are characterized by a shared property of 'newness.' In this paper we critically unpack NPS as a category and as a single object, bounded by a shared 'newness', and in so doing examine whose ways of knowing are afforded epistemological authority and the harms that can emerge from an overemphasis on pharmacological properties at the expense of everyday practice. Through a focus on buying and selling NPS discussed in interviews with five "at risk" populations in Scotland, we examine the ways in which NPS use can in fact be more usefully characterized by continuity with existing practices, relationships and identities than by novelty. This finding raises the question that if everyday practices are not characterized by newness, what makes new psychoactive substances new? Comparison of the discourses of pharmacologists and people who use them exposes contrasting claims about the 'reality' of NPS: while pharmacologists describe their own ways of knowing as real, they often downgrade the experiences of those who use them as mere belief; the reverse does not occur. A common epistemological hierarchy is shared between pharmacologists, and those who use NPS and work with them where everyday practices (often characterized by continuity) are devalued relative to pharmacological ways of knowing that foreground novelty. When services have finite resources, this epistemological authority has significant consequences: when attention is paid to the 'new' (attempting to gain mastery of an ever-shifting drug landscape) it is not being
\end{abstract}


paid to the ways in which NPS substances are consumed within wider contexts characterized more by continuity with 'traditional drug' use than divergence.

\section{Keywords}

New Psychoactive Substances; Drug Buying; Drug Dealing; Drug Treatment; Categorization; Scotland

\section{Introduction}

In this paper we ask for whom are New (or sometimes Novel) Psychoactive Substances (NPS) 'new' and in so doing begin to explore how NPS have become constituted as an object. It begins from the voices, experiences and practices of a group of primarily in-treatment current and former NPS users from across Scotland. The story they tell is rarely one of novelty. Rather, what emerges from their words are the myriad threads that tie NPS use practices to older, more established ones. In other words, for those who use them, or for this group at least, new psychoactive substances are not primarily constituted by their newness. If the everyday practices of those who use them are not shaped by newness, if the meanings ascribed to them by those who use them are not framed as new, by what processes, through the valuation of what sorts of knowledge, did they come to be characterized as new psychoactive substances? Where does this focus on newness come from? Whose epistemology matters?

We argue that through bringing the voices of those who use NPS into dialogue with other sets of practices, other ways of knowing NPS, we can begin to unpack the role 
of epistemological authority in knowing NPS and in constituting them as an object. The acronym 'NPS' - despite its surface-level ambiguities and vagueness - can be, and is used as if it means something, as if it has some sort of stable referent, as though it is a tangible object; it is this process of stabilization that reveals the knowledge practices that count, and those that do not.

This article takes inspiration from Annemarie Mol's The Body Multiple (2002) and her explorations into how reality does not precede a given object or practices, but is rather constituted by them. Following Mol, we shall explore how NPS are given coherence as an (often singular) object through the prioritization of pharmacological practices over users' practices, how the costs of these forms of epistemological authority are born by those least able to contest them and how treatment often suffers as a result.

\section{Multiplicity versus Singularity}

In her pioneering work The Body Multiple: Ontology in Medical Practice (2002), Annemarie Mol explores the ways in which medicine in general and atherosclerosis of the lower limbs in particular are constituted ${ }^{1}$, arguing that they are constituted not so much by meaning (what atherosclerosis 'means' to patients, doctors and others) but by practices. In other words, atherosclerosis is enacted by patients, surgeons, general practitioners and pathologists. It is through the ways in which

\footnotetext{
${ }^{1}$ Atherosclerosis refers to the build-up of plaque in the arteries, which narrows them and constricts the flow of blood to extremities.
} 
atherosclerosis of the lower limb is enacted - how these groups do atherosclerosis that it is brought into being as an object.

A necessary consequence of this focus on practice is multiplicity. The body can no longer remain singular in this analysis: for patients, atherosclerosis is brought into being through pain when walking; for surgeons by the lack of discernible pulse in the ankle and complaints of pain in walking and relief in rest; for pathologists by a presence of dye-illuminated plaque and an absence of lumen in a cross-section of an artery made visible through a microscope. It is a single thing - it is atherosclerosis but it is multiple. The multiple ways in which it is brought into being as an object, the diversity of ways in which it is enacted, mean that this thing, 'atherosclerosis', is not a single, straightforward object but an entity brought into being through the ways it is known: because those ways of knowing are always multiple, it is multiple also.

Thus for Mol, reality doesn't precede practices but is constituted through them. In this case, atherosclerosis is brought into being through various technologies, including but not limited to reports of pain, blood pressure cuffs, angiography and duplex testing. Often, these different ways of knowing atherosclerosis align and a decision can be made about whether to perform surgery or not. However, this is not always the case. And, 
If two objects that go under the same name clash, in practice one of them will be privileged over the other... To sustain the singularity of the object one signifier must be discarded. (2002, p.47, p.62)

Often this means that if patients' complaints of pain are at odds with medical tests they are disregarded. However sometimes two tests will produce conflicting results, and this needs to be resolved - Mol argues that powerful actors resolve such disputes through making ontological claims, such that one test can be claimed to only 'seem' to suggest a particular result while another reveals an 'in reality' truth. Until the surgery is performed the veracity of these truth-claims cannot be revealed; ontological claims make the realities they purport to describe.

What does a discussion on atherosclerosis contribute to understanding substance use? The objects, after all, could not be more different: one is a physiological consequence of diabetes, the other a set of substances for consumption. But in order to address for whom New Psychoactive Substances are new we need to understand what New Psychoactive Substances are. To do that, we need to look at how they are brought into being - and given coherence as a singular, comprehendible object (or not). In a twist of tautology, what coheres them is their newness - but it is newness of a particular order. As already noted above, and explored in further detail below, for those who use them NPS are rarely defined by their newness. Indeed NPS are rarely enacted as a single, coherent object at all. Rather, this work of constituting and boundarying NPS as a singular object has taken place elsewhere, in the annals of prestigious scientific journals. 
One of the most striking things in reading about NPS in academic publications across different disciplines is how self-evident NPS as a concept is taken to be, as illustrated by these examples of the opening sentences of academic papers, which do not then continue to provide a definition of NPS,

The last decade has seen a worldwide surge in the recreational use of novel psychoactive substances (NPS). (Zawikska, 2017, p. 1)

The increasing supply of novel psychoactive substances (NPS) is changing the drug market in a fundamental way. (Anderson \& Kjellgren, 2016, p. 283)

These scholars do not need to define NPS because they - and their reviewers and editors - already know what NPS means and know their readers will too, and that this understanding is a shared one. This is NPS object-making in action: treating NPS as a single, bounded entity makes it into a single, bounded entity.

However, it does not take much interrogation to expose the work required to do this. For example, Vaiano et al. (2016, p. 441) state NPS are "synthesized by altering the chemical structure of controlled compounds, in order to produce new unscheduled drugs." By this definition, they are first and foremost tweaked molecules seeking to simultaneously evade detection and/or classification and produce a pleasurable and profitable high. But Sutherland et al. (2017) draw attention to "older-new" drugs such as DMT (dimenthyltryptamine), synthesized long ago but only recently 
popularized, and ask if these should be included. Others wonder if natural-occurring substances such as Hawaiian baby woodrose, long used in indigenous communities but only recently popular in the West, should have their place alongside their synthesized brethren (Favretto et al., 2013; Tittarelli et al., 2015). Among those parties tasked with the boundary work, NPS resists easy definition.

Work has to be done to constitute NPS as an object - it did not emerge into the world, new, whole, and complete. However, new psychoactive substances often continue to be talked about as if they are not all these diverse things, but a selfevident reality. This conceptual unity in the face of diversity can perhaps be explained in terms of the definitions we found to be most commonly cited among scholars who do define what they meant by NPS:

A new narcotic or psychotropic drug, in pure form or in preparation, that is not controlled by the [United Nations drug conventions], but which may pose a public health threat comparable to that posed by substances listed in these conventions. (EMCDDA, 2006, p. 1)

Substances of abuse, either in a pure form or a preparation, that are not controlled by the 1961 Single Convention on Narcotic Drugs or the 1971 Convention on Psychotropic Substances, but which may pose a public health threat. (UNODC, 2013, p. iv) ${ }^{2}$

\footnotetext{
2 UNODC continues, stating "In this context, the term 'new' does not necessarily refer to new inventions but to substances that have been recently become available." However, this corollary is often missing when cited.
} 
Both of these highly congruent definitions define NPS as psychoactive substances not controlled by UN Conventions, and that may pose some sort of public health threat. While the covered/not covered by UN drug conventions is a relatively clear line, the latter clause is not - it is framed in terms of potentialities, rather than effects. Any 'new' thing, by definition, will have unknown effects, and this state of unknowability means that it could at some future point pose a public health threat.

Fraser and Moore (2011) explore this unknowability specifically in relation to amphetamine-type substances in Australia, exposing how they are constituted as both poorly understood and inherently dangerous. Barratt et al. (2017) pick up on this tension in relation to new psychoactive substances-related legislation in Australia, arguing that this simultaneous framing as poorly understood and inherently dangerous results in Australian policy "tend[ing] to treat NPS as a singular category of substance" $(2017$, p. 22) because of their perceived shared property of producing as-yet-unknown "psychoactive effects" in consumers.

In line with these scholars, we argue that NPS gets constituted as an object through definitional work that foregrounds unknowability. Within these frequently cited definitions, as long as a substance fulfils these three criteria - being a psychoactive substance, not covered by UN Conventions, and potentially posing public health harm (which they do by virtue of being as yet unknown and unknowable) - they become NPS. What all NPS have in common within this definition is a shared property of novelty: in prioritizing that over their diversity of effects, meanings to 
those who use them and the like they become singular. These definitions have powerful shaping effects because they are frequently cited and therefore easy to mistake for a description of what NPS are rather than a particular set of practices that bring NPS into being as an object.

Going further, attention must be paid to the choice of language - or more specifically the choice to use an acronym - to describe these objects. The label 'new psychoactive substances' builds the common property of novelty (and thus the forms of knowing that foreground novelty) into the language used to describe and group hitherto diverse substances. But the acronym NPS goes even further: the overt reference to plurality of 'new psychoactive substances' gets lost. It is even easier to mistake 'NPS' for a singular object than 'new psychoactive substances'.

Barratt et al. play with this when they say "in spite of the (apparently) fluid nature of NPS, it is constituted as a largely coherent object that 'hangs together', in Mol's terms, as a singular entity, thus obscuring difference" (emphasis added) (2017, p. 23). Like Barratt et al. (2017) and Fraser and Moore (2011), there is an emerging body of critical scholarship seeking to de-obscure that difference. Sumnall et al. (2017) highlight the diversity and complexity of both NPS pharmacology and effects, concluding that "it is too simplistic to consider these as one class of drug, although they are often popularly discussed as such." Soussan and Kjellgren (2016) similarly seek to desingularize NPS, doing so through examining motives for using NPS. By focusing on the practices of NPS users it emerges - in striking concordance with our own findings - that different motives adhere to different sorts of NPS. They too 
conclude that it is too simplistic to consider these substances as one class of drug. Potter and Chatwin (2018) ask similar questions about the apparent distinctiveness of NPS, questioning the utility of NPS as a category, arguing that:

the creation of the category [NPS] itself has resulted in significant consequences while having neither meaningful coherence or academic utility. (2018, p. 2)

This is borne out by Soussan and Kjellgren (2016) when they conclude that people who are drawn to different types of NPS have different routes into, through and out of use, and that "different pathways to drug use is assumed to be essential in enabling effective treatment, prevention and consequently a reduction in harm" (2016, p. 78). Thus when treatment and prevention services work within categories that prioritize pharmacological over practice-based ways of knowing, the outcome is not neutral, and indeed risks potentially harming those seeking support with their substance use.

In addition to making this important point, Potter and Chatwin argue that through creating the category 'NPS', the opposite, 'not-NPS', must also be brought into being. In this process of creating 'NPS' and 'not-NPS', 'NPS' must be understood as (a) having properties in common, and (b) being distinct from 'not-NPS.' For them, this process obscures far more than it reveals, and it does this by precluding other forms of sense-making. As noted above, this matters because prioritizing the practices through which newly emergent/rediscovered/popularized substances are constituted 
as 'new' is mutually exclusive with research practices that find them in existing categories and existing practices. A key example of this can be found in the Drugs Wheel (www.thedrugswheel.com), which was central to the definition of NPS used in this study, to which we now turn.

\section{Constituting Newness: A Methodological Undertaking}

This paper is a byproduct of another research project. Following a scoping review (Fraser, 2014), the Scottish Government commissioned a piece of empirical research to ascertain the prevalence, motives, and harms of NPS use in Scotland, with a view to inform policy (see [removed for review]). Fraser (2014) identified five groups at particular risk of engaging in NPS use:

- At-risk young people (age 16-21) - for example, care experienced, those not in education (YP)

- Homeless people (HP)

- Mental Health Service Users (MHSU)

- People who inject drugs (PWID)

- Men who have sex with men (MSM)

To garner a comprehensive understanding of this issue, a three-phased, mixed methods approach to data collection was taken. This article draws from the data collected in Phase One and Two: interviews with people who at the time of interview were using or had used NPS, and focus groups with frontline workers. In total, 32 interviews were conducted with 33 individuals, who fell into one or more of the identified "at-risk" groups. Interviews took place across mainland Scotland, primarily 
in recovery-oriented treatment settings (Scottish Government 2008, 2018); consequently, participants framed their discussion through a recovery paradigm, frequently describing their use in terms of a progression toward eventual achieved or aspired abstinence (Neale et al., 2011). The key exception to this was MSM, who were recruited online and in gay bars and none of whom saw themselves as being in or working toward recovery.

[TABLE 1 - see end of document]

For Phase Two, four focus groups with 42 frontline workers were undertaken across urban and rural Scotland; most (20) worked in a drug service, but participants also came from prisons, housing, homelessness, sexual, mental health and youth organizations.

[TABLE 2 - see end of document]

All interviews and focus groups took place between January and April 2016. This timeframe is significant as it followed the drafting, but preceded the implementation, of the Psychoactive Substances Act, which came into force in May 2016. Participants were asked about what they anticipated the effects of the Act to be. The Act defines Psychoactive Substances thus: 
any substance which (a) is capable of producing a psychoactive effect in a person who consumes it, and (b) is not an exempted substance ${ }^{3}$. (Psychoactive Substances Act 2016, s.2.1)

As a UK-wide piece of legislation, the Act signified the culmination of a series of shifts that had occurred in the months and years leading up to May 2016. A range of local ordinances led to the closure of shops selling NPS, thus when participants were asked about the then-forthcoming 'ban', they often answered retrospectively, reflecting on the impact of locally implemented by-laws prohibiting the legal sale of NPS in shops.

\section{Defining NPS: How particular substances came to be included in the study}

A particular challenge of the early stages of the project was anticipating that participants may not be familiar with the object 'NPS' and to identify which substances we were and were not interested in understanding the use of: in short which substances were and were not NPS for the purpose of this study (see Measham and Newcombe, 2016, on the impact of this lack of clarity on drug monitoring). Some substances were considered straightforward. Brightly colored packets of synthetic cannabinoids going by names such as Exodus, Black Mamba, and Clockwork Orange were bound up with new challenges experienced by services and the subject of a "moral panic" (Cohen, 1972), as numerous documentaries and

\footnotetext{
${ }^{3}$ Exempted substances are: controlled drugs (within the meaning of the Misuse of Drugs Act 1971), medicinal products, alcohol or alcoholic products, nicotine and tobacco products, caffeine or caffeine products and any substance which "is ordinarily consumed as food and does not contain a prohibited ingredient."
} 
newspaper articles described new social problems resulting from their existence (e.g. 'Horror as Lethal Spice "Zombie" Drug Epidemic Spreads among Homeless in Glasgow', Daily Record, 2017; 'Living Life as a "Zombie" on Spice', BBC, 2018). Similarly the new raft of stimulants going by names such as Charlie Sheen or GoGain (and designed - or at least marketed - as a licit alternative to scheduled stimulants such as cocaine), new empathogens such as mephedrone (designed, and originally marketed, as alternatives to ecstasy), and new psychedelics, which tend to go by names sounding closer to chemical formulae such as 25I-NBOME, 5-MeO-DMT or AlLAD were included.

However, the inclusion of some substances was debated. What, for example, is the place of salvia divinorum? What of the benzodiazepine family? Were these more usefully understood as plants, diverted pharmaceuticals or New Psychoactive Substances? Dwyer and Moore (2013), who used Law (2004) as a theoretical frame to unpack multiple ontological understandings of methamphetamines, explain: it is important to pay attention to the politics of what is made present and, correspondingly, what is absent, what is silenced, and what is made Other. (Dwyer \& Moore, 2013, p. 204)

Given the focus on policy, and thus the focus on harms, these substances were included because they had been identified to embody new problems in need of solutions, thus the definition finally adopted in the study was pragmatic, rather than conceptual. To understand NPS as an object required work: it was not a given and it was far from stable. 


\section{New Psychoactive Substances versus Legal Highs}

A further challenge posed by this project was what to call this pragmatically cohered group. The phrase most frequently used in research and policy is 'New Psychoactive Substances', a phrase deliberately chosen to distance itself from 'Legal Highs.' As has also been noted elsewhere (Measham \& Newcombe, 2016; Potter \& Chatwin 2018), the language of policy and research is that of novel or new psychoactive substances (NPS). Yet this phrase was next to meaningless for our study participants; it was a category (or object, Mol, 2002) that simply did not exist for them. Yet the alternative - 'legal highs' - was problematic because it appeared to place these substances on one side of a legal/illegal binary and whether a packet of a given substance comprised only licit substance(s) in that place, at that time, was far from certain (Frinculescu et al., 2017; Ramsey et al., 2010). Yet the language remained. While we avoided it, our study participants did not. They frequently spoke of "legal highs" and "legals" and even of being "legalled" (i.e. under the influence of a specific legal high). Participants did not necessarily mean the same thing when they used this term: some used 'legal highs' to refer only to synthetic cannabinoids; others to any drug bought in a shop; others to purchased prescription pharmaceuticals. Just as there was no stable NPS, there was no stable legal highs either.

\section{Analysing Newness}

The qualitative data discussed here were initially analyzed to identify motives for, and harms of, NPS use as identified by those who currently or formerly used them, 
and frontline staff who worked with them. Interviewees selected themselves into the study in response to the following wording on recruitment posters: "Have you ever taken a legal high or a New Psychoactive Substance? Are you aged 16 or over?" All had taken at least one substance defined as NPS for the purpose of the study at least one time. Participants were asked about: what NPS they had tried and where appropriate continued to use; positive and negative effects; attempts to stop use; experiences of treatment; and views on the (then-forthcoming) Psychoactive Substances Act. These interviews were then transcribed, anonymized and coded using Quirkos qualitative software for themes of motives for use and harms of use (Braun \& Clarke, 2006).

Following the initial analysis in 2016, data were coded again in 2018 for 'newness' for the purposes of this paper; 'newness' was not asked about directly in interviews. Transcript segments were initially coded as either 'new' or 'not new.' All codes were then checked against the available literature. Segments related to motives, such as 'being able to buy from a shop' or 'being able to sample many varieties before finding the one you like' were coded as 'new,' and 'concerns about purity' or 'recovery prompted by pivotal moment' were coded as 'not new.' This distinction was based on whether there was an established evidence base to show that these aspects of drug use experience precede the emergence of New Psychoactive Substances as an 'object' or not.

Using newness as an analytical category proved problematic: segments on such topics as 'being able to buy online' or 'being able to research options before buying' 
raised profound questions about what constitutes newness, and the ways in which new psychoactive substances are entangled with other processes, other developments, and other forms of newness. Some participants in this research distinguished NPS from their traditional forerunners because they could buy NPS online, yet other research notes that the Internet has long operated as a space where commodities both licit and illicit can be purchased (Martin, 2014; Masson \& Bancroft, 2018). Is the newness of being able to research or buy NPS online about 'new' substances, or 'new' communication technologies and online spaces? As Internet-enabled, mobile devices become increasingly popular and affordable, digital spaces have become more accessible and responsive to wider audiences. The technologies that underpin the production, consumption and knowability of NPS are not static.

\section{Ethical Considerations}

This study sought to understand people's experiences in their own terms. Recruitment materials used the language of both 'new psychoactive substances' and 'legal highs' and we worked closely with treatment providers to inform them of the study to aid recruitment of people who may use or have used NPS but did not use the language of NPS or legal highs to describe their practices. All interviews were conducted in places familiar to participants, usually in the treatment setting where they had been recruited, and all interviews were conducted by an interviewer with extensive experience of the drug treatment field. It was made clear to participants that they did not have answer any questions they did not want to, and could end the interview when they wanted. All interviewees were offered a $£ 10$ high street voucher 
to thank them for their time and, critically, their expertise. We began from the position that people who use drugs should be recognized as the experts in their own lives and that all expertise should be appropriately recompensed (Pickering, 2018). This project received ethical approval from the UK's Health Research Authority's National Ethics Service (Ref: 15/WS/0210).

\section{Threads Broken and Rewoven: Rupture, Continuity and the 'Arrival' of NPS}

As noted above, this is not a paper based on a 'general' NPS using population. With the partial exception of Men who have Sex with Men (MSM), our participants were marginalized, often multiply so. Many had experienced homelessness, many had - or had had - mental health problems; almost all were in contact with drug treatment services. Their stories, then, are particular stories. No interviewees described their first encounter with drugs as being with NPS; all were experienced drug users, the majority were polydrug users, and many described highly challenging lives and drug use practices.

Participants told us about using 'legal highs.' When probed, claims such as "I've tried every legal high basically there is" (John, $26, \mathrm{MHSU}$ ) or "when you take legal highs, the actual sniff" (Gary, 39, MHSU/HP) revealed that different participants used the phrase "legal high(s)" to refer to different things - and generally to the substance(s) that they personally consumed (in John's case synthetic cannabinoids, in Gary's, stimulant NPS). Substances outside their personal repertoire simply did not feature or warrant inclusion under the title 'legal highs.' 'Legal highs' resisted a shared 
reference point across those who used them, while being used as though mutually intelligible in an interview setting.

Further, when asked about the NPS or 'traditional' drugs they used, participants generally demonstrated a lack of understanding of, or indeed particular interest in, this distinction. As Thomas (45, MSM/PWID) demonstrated when he replied "speed" to the question "what did you use the first time you used a legal high or new psychoactive substance?", our interviewees were not always clear on whether the substances they used were NPS or not, or legal highs or not. Similarly, Luke (20, YP) included "downers" (a category in which he included cannabis), Valium, mephedrone, and Kryptonite (a synthetic cannabinoid) among the list of illegal drugs he had used. When asked specifically about the status of mephedrone, Hugh (61, MSM) explained that "they're all legal and that [he] had never paid much attention but that, yes, it's definitely not illegal," despite mephedrone being made a Class B drug in 2010.

However, this does not mean that our participants did not classify the substances that populated their personal drug landscapes. Far from it. These distinctions were just of a different order, and concerned with the everyday pleasures and practices of use, rather than where they stood on an NPS/traditional, or in most cases even a legal/illegal, binary: as Daniel, Peter and Andrea illustrate, our participants distinguished between drugs they would use again and drugs they would not, "junky" drugs and non-"junky" drugs, and substances suited or not suited to one's preferred route of administration. 
I thought it was a cannabis joint ... I started hiding under my bed for four days. It is something I wouldn't ever do again, it was actual crazy. (Daniel, $17, \mathrm{YP} / \mathrm{HP} / \mathrm{PWID})$

It [synthetic cannabinoids] was a total junky wee thing to do, man. I just don't know why these wee Goths ... sit and smoke it all the time because it was nasty, man. It was probably just as bad as fucking kit [heroin]. (Peter, $17, \mathrm{YP} / \mathrm{HP} / \mathrm{PWID})$

He [the shopkeeper] told us what the best [synthetic cannabinoid] would be to do, but he told us to smoke it, but we injected it. (Andrea, 34, HP/PWID)

In talking about the choices they made about the substances tried, continued with, and sought to stop using, participants merged NPS and 'traditional' drugs together. What mattered to them were distinctions related to their everyday practices and sense of identity.

\section{Sense-Making: Social Inequality \& Technological Advances}

Potter and Chatwin (2018) propose an alternative to pharmacological forms of sense-making predicated on locating specific, 'new' substances within broader societal (rather than chemical analytical) processes, drawing on two such processes by way of illustration. These are (1) social inequality and (2) technological change. To explore social inequality they use Alexandrescu's sociological analysis of NPS use 
in Romania to explore what happens when NPS is reframed not as driver of harms but as byproduct of other factors. Alexandrescu argued that when examined from this perspective, epidemics among vulnerable populations occur less because new drugs appear, than because of the "deeper, structural economic problems and inequalities" (2017: 1) that shape the lives of people who use NPS more generally. For both Alexandrescu $(2016,2017)$ and Potter and Chatwin (2018), these problems manifest in relation to whichever substances are available at the time, but are caused by deeper social issues. Focusing on the substance rather than underlying inequalities will necessarily produce findings that the substance - and specifically its novelty - is the cause of the social harms experienced by its already-vulnerable users. Refocusing attention to underlying structures reverses this and locates the use of a particular substance as an expression of, and response to, preexisting harms.

In our study, participant groups were selected because they were understood to already be at the sharp end of "structural ... problems and inequalities" and as a result particularly "at risk" of problematic NPS use (Fraser, 2014; [removed for review]). However, they did not understand themselves to be particularly "at risk" of NPS, nor consider themselves as "NPS users" at all in some cases. They were people who were in contact with drug services because they (or someone else) understood their substance use to be problematic in some way, or a barrier to achieving other goals. Whether it was ethylphenidate or heroin, cocaine or Ching, the solution to the 'problem' lay in recovery - the shaping concept of Scottish drugs policy and defined in the-then Scottish Drugs Strategy, The Road to Recovery (2008) as: 
a process through which an individual is enabled to move on from their problem drug use, towards a drug-free life as an active and contributing member of society. Furthermore, it incorporates the principle that recovery is most effective when service users' needs and aspirations are placed at the centre of their care and treatment. In short, an aspirational, person-centred process. $(2008, \text { p. } 23)^{4}$

For our participants, the 'NPS'/not-NPS' binary was, in practical terms, largely irrelevant. It was poorly understood and did little to shape their routes in, through, and out of substance use. However, when discussed with frontline workers, much talk addressed the ever-shifting NPS landscape and their knowability. As stated in the Glasgow focus group,

The type of NPSs out there, it's forever evolving, forever changing and it's being able to access up to date information.

This ongoing, shifting landscape was experienced by many frontline drugs workers as being substantially different to substances with longer histories of use:

Traditionally we'll say 'Heroin: this is the side effects, this is this, this is that, this is the withdrawal symptoms ...' but because there's such a plethora of

\footnotetext{
${ }^{4}$ The current Scottish Drug Strategy defines recovery as "a journey for people away from the harm and the problems which they experience, towards a healthier and more fulfilling life" $(2018$, p. 26).
} 
different chemicals and changing chemicals, what are you going to do? (Glasgow Focus Group)

Service users also experienced this; some interviewees commented on services' lack of knowledge:

They [drug service] didn't know enough about the synthetics [synthetic cannabinoids]. They knew bits and pieces maybe about powders and pills and they didn't know enough about synthetics to help me. (Kieran, 46, MHSU)

Kieran expressed frustration at the lack of knowledge within services about the particular substances he consumed. While the anxieties of the former may have been driven by the frustrations of the latter, there is a critical difference: people who use drugs tended to be concerned with knowledge about the specific substances they consumed, whereas workers expressed anxieties about NPS as a class made up of an ever-expanding panoply of specific substances. While workers could theoretically build their knowledge of specific substances, the fact that the class of substances known as 'NPS' consists of all 'new' drugs in a globalized network of fast turnaround development, production, transportation and consumption means that they simply cannot gain mastery of the class itself. As soon as they know all there is to know about the substances that comprise NPS in a given moment, the individual substances of which the group comprises has changed again (Measham \& Newcombe, 2016). 
The second alternative form of sense-making Potter and Chatwin focused on was technological change, asking what happens when we contextualize NPS as part of rather than outside of - wider processes of evolving chemical and horticultural techniques, and new media technologies. They concluded that within those contexts, NPS are "not particularly special." These technological changes have driven, and been driven, by new forms of social engagement spurred by Web 2.0, faster forms of international postage, smartphone technology, and the like. Within this, NPS is neither a driver nor consequence but intimately bound up in a complex of interlinked, technological innovations.

We support Potter and Chatwin's contention that "[i]t is not clear that anything objectively unites NPS in a way that delineates them from pre-existing categories of illicit drugs" (2018, p. 331), and it is this very lack of distinction that exposes the volume of work that is required to shore up 'NPS' against 'not-NPS', in turn, exposing the forms of knowing NPS that are foregrounded in seemingly abstract and universal 'definitions' of NPS. To do this, we focus on a single site of social and technological innovation - purchasing NPS - and how the utilization and evolution of these technologies are intimately bound up with more existential questions of knowability, and whose knowledge counts.

\section{Buying NPS}

There were three key routes participants described to access the substances we were interested in: shops, dealers, and the Internet. Headshops specializing in the sale of mainly cannabis-related drug paraphernalia were well positioned to adapt to 
the arrival of brightly colored packets of (at least temporarily) legal substances, likely to be of interest to their patrons. Six of the eight participants who described buying NPS in shops discussed buying synthetic cannabinoids, while the remaining two detailed buying Burst (ethylphenidate).

\section{Blurred Boundaries; Shops and Dealers}

Choosing Shops

The brick-and-mortar shop as a site of drug sales can be seen as a significant development in UK drug markets; they were a new space, through which new types of drugs characterized by 'reliability' and 'consistency' could be bought. It provided a means of accessing mood-altering substances not predicated on one's social networks.

Over his drug-using career, Luke (20, YP) had moved from consuming primarily cannabis to primarily synthetic cannabinoids to aspiring recovery at the point of interview. In addressing the appeal of synthetic cannabinoids, he discussed the ease of buying from shops,

It was just knowing that all you had to do was walk with my dog, run to that shop ... hand over the money, that was that. Guaranteed. Sealed packet. Not opened.

For Luke, the shop as a site of purchasing substances represented something new: it had predictable, reliable opening hours, and the products sold were "Guaranteed. 
Sealed packet. Not opened." Like any new development, it is only new in relation to that which preceded it (Hutton \& Farías, 2017), and this was no different for Luke. Luke began this discussion of buying synthetic cannabinoids from shops by talking about buying cannabis from dealers,

Getting a bag of weed, if it wasn't a regular dealer, it was like, 'What is this stuff going to be like? Can you trust him? Is it going to be on weight?'

Buying in shops were presented directly in contrast to the anxieties of finding a dealer, ensuring quality assurance and avoiding being 'ripped off.' The shop as site of security - as 'new' - emerges from this contrast.

For others, shops were a site of asociality: as one of the three participants who described eagerly awaiting the arrival of the Psychoactive Substance Act explained,

Nobody I knew smoked it [synthetic cannabinoids]. And up to this day, I've not been in contact with anybody face-to-face that smoked it ... If the shop haven't got it, I'm not going to go to dealers, cos I don't know dealers. (Kieran, 46, MHSU)

Kieran, like some others who bought exclusively in shops, did not know any street dealers and anticipated the banning of shop sales as foreclosing the only available route to accessing their substance(s) of choice. 
One possible consequence of this emergent technology of purchase might have been that dealers, seeing a loss of business from people like Luke, changed their practices to become more shop-like. However, this is the reverse of the pattern that emerged from our participants' accounts. Instead, shops came to increasingly resemble dealers. Participants described shop keepers who would sell to them 'on tick' (i.e. sold on the agreement that the buyer would pay for the goods at a future point); shops coming to mirror the hours in which buyers bought from dealers; and shops undermining the very thing Luke valued ("Guaranteed. Sealed packet. Not opened") by taking sealed packets that retailed at $£ 10$ a packet and splitting them into two for sale at $£ 6$ each to cater for lower income and customers who operated on a shorter temporal loop. As Nicola (32, PWID) explained,

The shops that were selling them, they started just acting like your dealer because then they were putting signs outside their shops, deliveries and everything, so they were just like a dealer, you'd be able to phone them at any time and then they'd come and meet you.

Thus when thinking about the ways in which new practices constitute a new object, shops both did and did not constitute NPS as 'new.' The "guaranteed" nature of the transaction and independence from existing social networks that marked shops out as distinct from dealers helped constitute the substances sold within them as 'new.' They produced new user groups and new problems, both in need of solutions while also quickly adapting to local markets, adopting dealer-like characteristics. 


\section{Choosing Dealers}

Despite the availability of shops, dealers still retained their predominant position in the drug-using careers of our participants. Many discussed preferring the familiarity of buying from dealers even when they knew that more mainstream alternatives existed. Andrea (34, HP/PWID) explained that:

If you couldn't get it [Magic - ethylphendiate] from anybody here, which was quite unusual, there was the shops in [town] that you could go to.

For Andrea and others, shops were a resource - but a resource of last resort. Their reluctance to choose shops is a reminder that the existence of new technologies such as shops does not necessarily produce uptake of those technologies - if anything, the emergence of shops as a site of sales exposed the durability of traditional and established forms of exchange.

But what of the "guaranteed" qualities of shop-vended products in relation to dealersold ones? As previously noted, this was not a quality equally valued by all participants like Luke (20, YP) saw this as a noteworthy and preferential difference from buying from dealers, but other participants prioritized price and ease of access over questions of quality control and consistency. Jessica (35, HP/PWID) reflected on the knowability of Magic [ethylphendiate] when bought from a dealer (her preferred route): 
[I bought Magic] through a dealer, and so I've not got a clue what I was taking ... it might have been different ones, and that's where the varying hit comes from, I don't know. I just knew it as Magic ... it could have been anything.

Akin to toxicological discussion of the composition of NPS brands (see, for example, Measham, 2019; Ramsey et al., 2010; Smith et al., 2015), Jessica experienced the composition of Magic as variable in both effects and strength: it was both qualitatively and quantitatively unstable. However, this unknowability was not a product of NPS, it was not new; it was a familiar feature of buying from dealers (Lakhdar et al., 2013). Indeed, Magic's unknowability was consistent with Jessica's expectations of what the process of buying and using substances was like:

I was already doing that [using without knowing what it was cut with] with heroin ... We know heroin is cut with loads of crap, we know that it does awful things to us but we still use it. (Jessica, 35, HP/PWID)

What is particularly striking about the ways that Jessica and Andrea talked about buying Magic of variable quality from dealers was that they knew they could buy it in a shop if they had wanted to. They could have had, or at least pursued, the same "guaranteed" experience that Luke did. It was about choice, in a space where choice was typically limited by one's resources and connections. And they chose not to. 
Choosing Online and the Emergence of (not so) New Mediating Roles

While the 'legitimacy' of shops attracted some, it repelled others. Through this, new mediating roles emerged. This can be located in a wider set of trends away from dealer/consumer binaries towards new forms of distribution through 'social supply', 'sorting' and the like (Coomber et al., 2016; Parker, 2000). Three participants raised at least partially financing their own use by buying substances for others and being "given" a cut in exchange. Moira (39, PWID) described sourcing mephedrone for friends and acquaintances too wary to go into shops "in case they got attacked":

I started, like I was able to go and get it [mephedrone], so folk would come to me, 'Moira, do you want to go and get it?' ... At the end, my habit was funded cos everybody was coming, and I was taking a fiver off everybody, they were giving me bits, and all the rest of it.

Shops, then, did not replace prior social networks of dealing, supply and 'sorting' but came to be embedded within them. Nor did the Internet. Rather, the emergence of brick-and-mortar and online shops created new niches for individuals to occupy within the flows between producers and consumers. Tiffany (28, MHSU) and Samuel $(19, \mathrm{YP} / \mathrm{HP})$, along with several of the younger participants, had discovered that buying online afforded better quality at a better price, but also that, as Tiffany says,

I can make money [when] somebody else orders something or I order something for them and get it and then they give me, whatever, a couple of joints' worth. 
Like Moira, Tiffany discovered that the capacity to function as an intermediary between vendor and consumer enabled her to "make money." Samuel (19, YP/HP) reflected at length on this intermediary role and the barriers to accessing online sales that existed for some consumers:

In [small town] you get quite a lot of folk that are getting it through dealers. But like there's a few people, like a certain handful of folk that know about online and have got the money to just frequently get it online...but most people that are drug addicts - like it's the same with smack [heroin] - they're just buying tenner [£10] bits on the street.

Why do you think people buy from the streets rather than...?

Because they can't afford it online. Plus they don't understand it, right, where to get it from online, what websites, and plus they might not have an account or they might not have enough money in their bank, plus they want it there and then, they don't want to have to wait a day or two to get it, you know what I mean?

Alistair (28, MHSU) was such a person. He knew that it was possible to buy the substances he wanted at a cheaper rate online, but he just could not build up the necessary "lump of money" to buy this way, explaining:

I just get it off folk on the street...folk just sell it outside. And is it cheaper? 
$£ 6$ a gram, $£ 6$ a gram...You can get it cheaper online if you buy it in bulk. You can buy 100 gram online for about three or four hundred quid.

Why do you choose to buy it from people you know?

I've never got a lump sum of money to go and buy it online.

Like Alistair, Samuel flags up the lack of economic capital as a barrier, but also other potential barriers such as having a bank account, the necessary skills and knowledge and - critically - the patience to wait for delivery. Even though new forms of purchase were available and known about, they remained inaccessible or lesspreferred to buying within an established in-person social network for many.

For our participants, using the Internet to purchase NPS reflected wider generational patterns of Internet usage (see Bolton et al., 2013; Joiner et al., 2013; Orsolini et al., 2015 on NPS). However, as Samuel highlights, these new forms of connectedness depend on a range of factors, including digital literacy (Rowsell et al., 2017), physical resources such as owning relevant hardware, and financial resources to both pay for access and to purchase the substance itself. As Warf (2012) notes, there are many factors that make up the "digital divide" and our participants reflected this diversity. While those who were more open to buying online tended to be of the "digital native" generation ${ }^{5}$ and more familiar with using technology in their everyday lives, they had far from consistent views on the value of the online sphere:

What do you prefer about online?

\footnotetext{
${ }^{5}$ See Prensky's (2001) discussion of 'Digital Natives' and 'Digital Immigrants'.
} 
It's a lot cheaper, I can make money. It's a lot cheaper. Ten gram of really good stuff for $£ 25$ compared to three gram of shit for $£ 20$. It doesn't even compare, do you know what I mean? (Tiffany, 28, MHSU)

No I never bought on line, no.

Ok, any particular reason you didn't?

I don't trust the Internet, as much as a I love it I don't trust it. (Colin, 27, MHSU)

The choices people made about where to source their NPS were not automatic responses to particular substances or to the emergence of 'new' technologies. They reflected the social worlds with which people were familiar - and new technologies such as brick-and-mortar and online shops fitted into that existing social world. They attracted some, but felt alien or inaccessible to others; they facilitated the development of new intermediary roles based on existing relationships.

Locating this within Potter and Chatwin's analysis opens up space to decenter the substance, and foreground relationships to explore the continuities over the ruptures. Viewed through a substance-specific lens, NPS can be seen to drive new social spaces (brick-and-mortar and online shops) and new relationships (with shopkeepers, new kinds of intermediaries, and online vendors). Look through an online retail-specific lens, however, and patterns of access to NPS become a byproduct rather than a driver of change. Using the Internet to buy and sell goods vastly predates the emergence of NPS (for example, Amazon and eBay launched in 
1994 and 1995 respectively). Despite the closure of brick-and-mortar shops and the banning of online sales with the passing of the 2016 Psychoactive Substances Act, NPS continue to be purchased in the UK with relative ease in online shops on both the Clear-Web (the visible, search engine-indexable, easily accessed part of the web) and Dark-Web (sites not accessible through traditional browsers or traditional search engines, access to which requires specialist knowledge and equipment). Strikingly, such sites resemble and mimic the features - such as escrow and vendor and buyer star ratings - of Amazon (and Amazon Marketplace) and eBay (Barratt, 2012; Martin, 2014). From the perspective of online retailing, rather than substance use, then, NPS can be seen as just other commodities purchasable online. As Michelle $(16$, YP) recounts, the rhythms of shopping for synthetic cannabinoids as a person who lives near but not in a major city mirrors those of almost any other commodity:

[I buy it] off the Internet, or there's a shop in [city] we got it from a few times ... Whenever like me and my pals went down to [city] we'd always stop in at the shop but if we didn't go down to [city] we'd order it off the Internet every couple of days.

Online retailing has become increasingly sophisticated, building upon the foundations laid by Amazon and eBay over 20 years ago. Michelle's narrative highlights the ease with which consumption can work in 2019, and the ease with which some can switch between brick-and-mortar and online shops for the commodities (be they NPS or not) they wish to consume. 
In discussing why they used online stores, our participants discussed assuming that producers refine their product in response to consumer feedback, shopping around until you find the product that suits you, and being able to research products online before you bought them. Viewed through a substance lens, these are 'new' features; they represent a rupture with dealer-bought, 'traditional' drugs. Yet when viewed through a technologies lens, they are not new at all. Amazon, eBay and the like have long had customer reviews and vendor ratings built into their platforms; peer-led forums in which users of different substances can share their experiences and seek advice have a history almost as long as the Internet itself. All these practices are practices that many people, and particularly young people for whom the Internet has been a part of the social landscape their whole lives, already engage in in other aspects of their lives. You can shop around for drugs as easily as for shoes; you can research which new NPS to try next as easily as researching a new biro. Thus when we de-center pharmacology in favor of practices, NPS do indeed emerge as not particularly special, and do emerge as not particularly new.

Taking Potter and Chatwin's call to displace the centrality of substance in addressing NPS use opens up alternative perspectives directed toward underlying social structures and inequalities or developing technologies. By exploring in some detail how our participants bought (and occasionally sold) NPS we have been able to decenter substance in favor of technologies - in this case technologies of acquisition - to provide empirical weight to Potter and Chatwin's claims and open up ways of thinking about NPS that expose (and in exposing, create) them as neither particularly new nor particularly special. 
This process of exposing a reality of NPS use characterized by continuity over rupture and by forms of social relationships over forms of substance is an attempt to create that reality also. That reality comes into conflict with ways of knowing, ways of making truth-claims about NPS that do center on substance, and do center on the new.

\section{Epistemological Authority and the Knowability of NPS}

NPS are rendered knowable in a range of ways. For Jessica and her peers, who preferred to buy their Magic (ethylphenidate) from dealers than from shops, the very inconsistency of the substance as they consumed it and the varying hit it produced was what made it familiar for them. It was easy to draw comparisons with the heroin it supplanted in their drug use repertoire as it was variable, inconsistent, and "cut with loads of crap too;" it was the very inconsistency of ethylphenidate that made it consistent, predictable and knowable.

By contrast, individuals such as Luke framed the knowability of the NPS they used very differently. For this group, knowability resided in the familiarity of shops: in their layout and appropriate relations between shopkeeper and customer; and in the homogeneity of product: just as McDonald's produces "predictable food" (Ritzer, 2013, p. 97) through a consistent and identical process, so too did NPS manufacturers. However, just like McDonald's food, while you can control even the width of a pickle slice, ultimately there will always be marginal unpredictabilities when it comes to ingredients, but, "Whatever the (slight) unpredictabilities in the 
food, the packaging... can always be the same and imply that the food will be, too" (Ritzer, 2013, p. 97). These were drug consumers immersed in a social world of product standardization, and product standardization signaled through consistency of packaging.

Packaging shapes expectation. As Moerman (2002) has explored in relation to pharmaceutical medicines, "placebo effects" (a term he rejects in favor of "meaning responses") abound. He cites multiple studies showing that people feel the effects of both active and inert medications differently depending on color, tablet or capsule form, packaging and more. He attributes the effect of aspirin to "a combination of the actions of the acetylsalicylic acid, and the meaning of the pill and, perhaps, its brand name" (2002, p. 70-71). Moerman argues persuasively that "meaning response ... is a cultural phenomenon" $(2002$, p. 71$)$ and that attempts to locate the efficacy of a particular drug in its pharmacological properties misses the complex ways in which drug effect are shaped by expectation and the meanings nexuses within which they move.

"Meaning response" in combination with "McDonaldization" enable us to think about pharmacological effects in context - in the context of packaging, and the wider realm of shared symbols. This gained expression in varying ways, but primarily through the pursuit of something "better", or for finding the brand that worked for you after a period of exploration: 
Obviously using Ching [NPS stimulant, marketed as similar to cocaine] consistently you get used to it so you don't get the same hit so you move onto something, well obviously better. (Claire, 30, HP/MHSU/PWID)

I tried every legal high [synthetic cannabinoid] basically there was. And then I was Exodus man, I just found that that that was better than all the rest of them, so now I'm still on it. (John, 26, MHSU/PWID)

Viewed pharmacologically, this expectation of consistency was often misplaced. Indeed, lab testing of the contents of these packets has shown that packets do not always display their ingredient(s), and where they do, "for most brands, serious mislabelling was encountered" (Frinculescu et al., 2017, p. 330). Where this happened, stated contents could be substituted with substances licit (Davies et al., 2012), illicit (Smith et al., 2015) or both; and that "there is poor consistency in the contents of legal highs purchased over the internet" (Ramsey et al., 2010, p. 778), differing between vendors (Wood et al., 2012), between packets, and even within them (Frinculescu et al., 2017). As a result,

Even when users believe that they are buying the same product, a number of studies have shown that the active ingredients may change with time. (Wood et al., 2012, p. 1125)

Thus the experiences of our participants who bought such packets provided were strikingly at odds with the experiences of lab technicians. To return to Mol, they 
were one object with two competing realities. How can this disjuncture be accounted for? Which reality wins? Which one is the reality, which is the rea/nature of this object? And who has the authority to make those claims and be taken seriously? In attending to the language through which those who talked or wrote about their understandings make their claims it becomes clear that everyone was making claims about the true nature of NPS, but that these claims were framed somewhat differently.

The NPS buyers and users with whom we spoke made ontological claims about their substances of choice - they knew them to be consistent within and between packets and for this to be true; they did not make claims of any sort about other ways of knowing and consequent truth-claims about NPS. From this perspective, there was only one object and one reality; adjudication between competing realities was not required. By contrast, pharmacological research is specifically interested in adjudicating between these competing realities (and thus ways of knowing what is really in NPS packets). In Wood et al. (2012, p. 1125), for example, readers are told that people who use NPS "believe they are buying the same product" (emphasis added) while laboratory testing reveals the "actua/ contents of the products" (emphasis added).

At this point it is useful to return to Mol (2002) and her argument that when two ways of knowing a single reality come into conflict (such as when patient accounts of pain conflict with test results) one truth-claim is given precedence of the other, and that is usually the truth-claim of the doctor over that of the patient, but critically 
the way this is done is key: she argues that one must be dismissed as belief to enable the other to stand unopposed as true, as the (singular) reality. And just as bodily ways of knowing atherosclerosis are usually dismissed by holders of medical expertise in favor of their own technologically informed knowledge as the knowledge of the patient's body, so too here we see technologically mediated forms of expert pharmacological knowing being brought into conflict with bodily mediated forms of personal experiential knowing by those who use them. And here too, the latter is dismissed by the holders of pharmacological expertise in favor of their own knowledge as the knowledge of the properties of NPS substances and packets. Users believe, pharmacologists know. At least according to pharmacologists. While expressed with the best of public health motives, the language of actuality and belief assert an epistemological authority from a position of authority. In that process, users' own understandings of their bodies and what they put in them are, at best, devalued and dismissed as mere "belief" when it comes into conflict with what "actually" happens.

This slippage produces significant consequences, and both drug service users and providers shared a common set of anxieties about drug services' inability to provide their clients with appropriate support, because they lacked the appropriate knowledge of NPS. When NPS are framed as a set of substances that share structural novelty in common, that are understood as ever-evolving, ever-changing and internally inconsistent, what both clients and providers wanted was for providers to have mastery of the pharmacological properties and physiological effects of each substance: 
I think it's about getting up-to-date information as well. Because, you know, the type of NPSs out there, it's forever evolving, forever changing and it's being able to access up-to-date information. (Glasgow Focus Group)

It's just recently everybody seems to [be] taking them [NPS] so they [services] probably don't ken [know] much about them. The likes of kit [heroin] and all that, they sort of know the stages, like what you're going to be like if you never had the stuff, but with that [NPS] they don't really ken. (Nicola, 32, PWID)

And this produces solutions to the 'problem' (Bacchi, 2009) of NPS's unknowability, based on technological innovation, and specialists in NPS pharmacology. Yet we argue that these solutions, were they even possible, would not solve the 'problem' of NPS, because drug treatment services do not exist only as a source of information, but also of particular kinds of support. As one participant noted in Glasgow,

I know we're talking about NPS particularly this morning because that's what it's about but, you know, think how we talk about dependency issues in general, you know, that people, it's all come up, all the same things that haven't been new, in terms of health issues, mental health issues in particular, access to support, to empathy, to housing, where it all comes, that's the mixture of what people are looking for, not drugs-specific answers 
and we get hung up on drug-specific answers. (Glasgow Focus Group, emphasis added)

As this frontline worker notes, it is easy to "get hung up on drug-specific answers," and in that process to overlook that in terms of the social problems people present with (for example, physical health, mental health, housing), these are "all the same things that haven't been new." This has led some services to invest their energies in reinforcing existing skills:

We've certainly had to adapt our service because of the prevalence of NPS and the approach we take is we'll use Motivational Interviewing, then we'll look at building a relapse prevention strategy with them, look at other supports you can put in place ... With other drugs there is treatment pathways that you can go down, whereas for us, we've got to rely on the skills within the team to try and manage that and get them to take control of it. (Lothian Focus Group)

NPS are new substances, but they do not necessarily produce new problems. As critical observers such as Alexandrescu (2016) and Potter and Chatwin (2018) have noted, the specific forms of harm may be new, but at a deeper level the ongoing challenges of problematic substance use and addiction relate to housing, human connection, physical and mental health. In a world where it simply is not possible to know the medium- to long-term effects of a newly emergent substance, it is possible to place person-centered care at the heart of drug treatment, and to work with 
clients to achieve their personal goals. Person-centered approaches that locate the individual as the expert on their own life and look for continuities with the harms and hopes of substance use and recovery rather than the new enable services to bypass the epistemological authority of pharmacological ways of knowing and celebrate their own forms of expertise for the benefit of their clients.

\section{Conclusion}

Epistemological authority lies at the heart of 'new psychoactive substances.' Mol (2002) has shown that in medicine at least, the epistemological authority of technologically mediated scientific ways of knowing almost always displace bodilymediated patient ways of knowing. She shows how atherosclerosis emerges as a particular sort of object through these relations, and that the 'reality' of atherosclerosis reflects the power dynamics of these relations. NPS similarly emerges as an object through the high value placed on scientific, and specifically pharmacological, ways of knowing. Attendance to these ways of knowing exposes these substances as new, as pharmacologically novel. Yet as this paper has sought to show, this is not the only way to know these substances, and attendance to the most marginal voices in these discussions - those of those who use them - shows continuity, not rupture. Listening to their stories does not construct these substances as new, but rather shows the ways in which the effects of these substances on people's lives are not the site of dangerous, threatening unfamiliarity, but something that can be managed through person-centered treatment approaches. 
The epistemological authority of science over the subjective accounts of people who use drugs is not, then, merely interesting, and certainly not benign, but is itself a site of harm. Those possessing the authority to publish peer-reviewed, high-impact publications have power. Much of this work asserts a particular reality of NPS that bounds 'new' drugs from 'old' and prioritizes pharmacological ways of knowing over bodily or social ways of knowing. While those ways of knowing continue to be dismissed as mere "belief" and the continuities of everyday practices are devalued, treatment providers miss an opportunity to engage with people who use NPS in the terms they can engage with: meaning, values and hopes for a better future. There is a growing body of critical research into NPS committed to resisting the singularity of NPS - and through attention to the multiplicity of NPS we can begin to attend meaningfully to the multiplicity of people bringing them into being.

\section{References Cited}

Alexandrescu, L. (2016). Legally high, officially lost: Injecting NPS use and drug abjection in post-communist Romania. (PhD thesis). Lancaster University.

Alexandrescu, L. (2017). Spice is not the real problem, it's the way we look at poverty. Retrieved March 25th, 2019 from: http://volteface.me/features/spice-realproblem-poverty/.

Anderson, M. \& Kjellgren, A. (2016). Aspects of Substance Displacement: From Illicit Drugs to Novel Psychoactive Substances. Journal of Addiction Research and Therapy, 73), 283-285. doi:10.4172/2155-6105.1000283. 
Anon. (2017). Horror as Lethal Spice "Zombie" Drug Epidemic Spreads among Homeless in Glasgow. Daily Record, May 5 th. Retrieved March 25th 2019 from: https://www.dailyrecord.co.uk/news/scottish-news/horror-lethal-spice-zombie-drug10339888.

Anon. (2018). Living Life as a "Zombie" on Spice [Video]. BBC News, July $16^{\text {th }}$. Retrieved March 25th 2019 from: https://www.bbc.co.uk/news/av/uk-wales44852322/living-life-as-a-zombie-on-spice.

Bacchi, C. (2009). Analysing policy. Pearson Higher Education AU.

Barratt, M. (2012). Silk Road: eBay for Drugs. Addiction 1073), 683. doi:10.1111/j.1360-0443.2011.03709.x

Barratt, M. J., Seear, K., \& Lancaster, K. (2017). A critical examination of the definition of 'psychoactive effect'in Australian drug legislation. International Journal of Drug Policy, 40, 16-25. doi:10.1016/j.drugpo.2016.10.002

Bolton, R. N., Parasuraman, A., Hoefnagels, A., Migchels, N., Kabadayi, S., Gruber, T., Loureiro, Y. K., \& Solnet, D. (2013). Understanding Generation Y and their use of social media: a review and research agenda. Journal of Service Management, 24(3), 245-267. doi:10.1108/09564231311326987. 
Braun, V. \& Clarke, V. (2006). Using thematic analysis in psychology. Qualitative Research in Psychology, 3(2), 77-101. doi:10.1191/1478088706qp063oa

Cohen, S. (1972). Folk Devils and Moral Panics. Abingdon: Taylor and Francis.

Coomber, R., Moyle, L., \& South, N. (2016). The normalisation of drug supply: The social supply of drugs as the "other side" of the history of normalisation. Drugs: Education, Prevention, and Policy 23(3), 255-263. doi:10.3109/09687637.2015.1110565

Davies, S., Lee, T., Ramsey, J., Dargan, P. I., \& Wood, D. M. (2012). Risk of caffeine toxicity associated with the use of 'legal highs' (novel psychoactive substances). European Journal of Clinical Pharmacology 68(4), 435-439. doi:10.1007/s00228-011$1144-y$.

Dwyer, R., \& Moore, D. (2013) Enacting multiple methamphetamines: The ontological politics of public discourse and consumer accounts of a drug and its effects. International Journal of Drug Policy 24, 203-211. doi:10.1016/j.drugpo.2013.03.003.

European Monitoring Centre for Drug and Drug Addiction (2006). Monitoring New Drugs. Retrieved March 26 ${ }^{\text {th }}, 2019$ from:

http://www.emcdda.europa.eu/system/files/publications/408/Monitoring new drugs 72902.pdf. 
Favretto, D., Pascali, J. P., \& Tagliaro, F. (2013). New challenges and innovation in forensic toxicology: Focus on the "New psychoactive substances". Journal of Chromatography A 1287, 84-95. doi:10.1016/j.chroma.2012.12.049.

Fraser, F. (2014). New Psychoactive Substances: evidence review. Edinburgh: Scottish Government Social Research.

Fraser, S., \& Moore, D. (2011). Governing through problems: The formulation of policy on amphetamine-type stimulants (ATS) in Australia. International Journal of Drug Policy, 22(6), 498-506. doi:10.1016/j.drugpo.2011.09.004.

Frinculescu, A., Lyall, C. L., Ramsey, J., \& Miserez, B. (2017). Variation in commercial smoking mixtures containing third-generation synthetic cannabinoids: Identification and quantification of third-generation cannabinoids. Drug Testing and Analysis, 9(2), 327-333. doi:10.1002/dta.1975.

Hutton, M and Farías, I. (2017). Sourcing newness: Ways of inducing indeterminacy. Journal of Cultural Economy, 10: 434-499. doi:10.1080/17530350.2017.1326969.

Joiner, R., Gavin, J., Brosnan, M., Cromby, J., Gregory, H., Guiller, J., Maras, P., \& Moon, A. (2013). Comparing First and Second Generation Digital Natives' Internet Use, Internet Anxiety, and Internet Identification. Cyberpsychology, Behavior, and Social Networking, 16(7), pp. 549-552. doi:10.1089/cyber.2012.0526 
Lakhdar, C. B., Leleu, H., Vaillant, N. G. \& Wolff, F. C. (2013). Efficiency of purchasing and selling agents in markets with quality uncertainty: The case of illicit drug transactions. European Journal of Operational Research, 226: 646-657.

Law, J. (2004). After method: Mess in social science research. Routledge.

Martin, J. (2014). Drugs on the Dark Net: How Cryptomarkets are Transforming the Global Trade in Illicit Drugs. Basingstoke, Hampshire: Palgrave Macmillan.

Masson, K., \& Bancroft, A. (2018). 'Nice people doing shady things': Drugs and the morality of exchange in the darknet cryptomarkets. International Journal of Drug Policy 58, 78-84. doi:10.1016/j.drugpo.2018.05.008.

Measham, F. C. (2019). Drug safety testing, disposals and dealing in an English field: Exploring the operational and behavioural outcomes of the UK's first onsite 'drug checking' service. International Journal of Drug Policy, 67: 102-107. doi:10.1016/j.drugpo.2018.11.001.

Measham, F. C. and Newcombe, R. (2016). What's so 'new' about new psychoactive substances? Definitions, prevalence, motivations, user groups and a proposed new taxonomy. In T. Kolind, B. Thom \& G. Hunt (Eds.) The SAGE handbook of drug 
alcohol studies: social science approaches (pp. 576-596)

doi:10.4135/9781473921986.

Moerman, D. E. (2002). Meaning, Medicine and the 'Placebo Effect'. Cambridge:

Cambridge University Press.

Mol, A. (2002). The Body Multiple: Ontology in Medical Practice. Durham, NC: Duke University Press.

Neale, J., Nettleton, S., and Pickering, L. (2011). What is the role of harm reduction when drug users say they want abstinence? International Journal of Drug Policy, 22: 189-192. doi:10.1016/j.drugpo.2010.09.007.

Orsolini, L., Francesconi, G., Papanti, D., Giorgetti, A., \& Schifano, F. (2015). Profiling online recreational/prescription drugs' customers and overview of drug vending virtual marketplaces. Human Psychopharmacology: Clinical and Experimental, 30:4, 302-318. doi:10.1002/hup.2466.

Parker, H. (2000). How young Britons obtain their drugs: Drugs transactions at the point of consumption. Crime Prevention Studies 11, 59-82.

Pickering, L. (2018). Paternalism and the Ethics of Researching with People who use Drugs. In R. Iphofen \& M. Tolich (Eds.) The SAGE Handbook of Qualitative Research Ethics (pp. 411-425). 
Potter, G. R. \& Chatwin, C. (2018). Not particularly special: critiquing 'NPS' as a category of drugs. Drugs: Education, Prevention and Policy, 25(4), 329-336. doi:10.1080/09687637.2017.1411885.

Prensky, M. (2001). Digital Natives, Digital Immigrants: Part 1. On the Horizon, 9(5), 1-6. doi:10.1108/10748120110424816.

Ramsey, J., Dargan, P., Smyllie, M., Davies, S., Button, J., Holt, D., \& Wood, D. (2010). Buying 'legal' recreational drugs does not mean that you are not breaking the law. QJM: An International Journal of Medicine 103(10), 777-783. doi:10.1093/qjmed/hcq132.

Ritzer, G. (2013). The McDonaldization of Society: 20th Anniversary Edition. Thousand Oaks, CA: Sage.

Rowsell, J., Morrell, E., \& Alvermann, D.E. (2017). Confronting the Digital Divide: Debunking Brave New World Discourses. The Reading Teacher, 71(2), pp.157- 165. doi:10.1002/trtr.1603.

Scottish Government. (2008). The Road to Recovery: A New Approach to Tackling Scotland's Drug Problem. Edinburgh: Scottish Government. 
Scottish Government. (2018). Rights, Respect and Recovery: Alcohol and drug treatment strategy. Edinburgh: Scottish Government.

Smith, J. P., Sutcliffe, O. B., \& Banks, C. E. (2015). An overview of recent developments in the analytical detection of new psychoactive substances (NPS). Analyst 14(15), 4932-4948. doi:10.1039/c5an00797f.

Soussan, C. \& Kjellgren, A. (2016). The users of novel psychoactive substances: Online survey about their characteristics, attitudes and motivations. International Journal of Drug Policy 32, 77-84. doi:10.1016/j.drugpo.2016.03.007.

Sumnall, H., Hamilton, I. \& Monaghan, M. (2017). Novel Psychoactive Substances: Important Information for Health Professionals [Blog Post]. National Elf Service, March $3^{\text {rd }}$. Retrieved March 25 $5^{\text {th }}, 2019$ from:

https://www.nationalelfservice.net/mental-health/substance-misuse/novelpsychoactive-substances-important-information-for-health-professionals/.

Sutherland, R., Bruno, R., Peacock, A., Dietze, P., Breen, C., Burns, L., \& Barratt, M. J. (2017). New psychoactive substances: Purchasing and supply patterns in Australia. Human Psychopharmacology: Clinical and Experimental, 32(3), e2577. doi:10.1002/hup.2577. 
Tittarelli, R., Mannocchi, G., Pantano, F., \& Romolo, F. S. (2015). Recreational use, analysis and toxicity of tryptamines. Current Neuropharmacology, 13(1), 26-46. doi:10.2174/1570159X13666141210222409.

United Nations Office on Drugs and Crime. (2013). The Challenge of New Psychoactive Substances. Retrieved March 26 ${ }^{\text {th }}, 2019$ from: https://www.unodc.org/documents/scientific/NPS_2013_SMART.pdf.

Vaiano, F., Busardò, F. P., Palumbo, D., Kyriakou, C., Fioravanti, A., Catalani, V., Mari, F., \& Bertol, E. (2016). A novel screening method for 64 new psychoactive substances and 5 amphetamines in blood by LC-MS/MS and application to real cases. Journal of Pharmaceutical and Biomedical Analysis, 129, 441-449. doi:10.1016/j.jpba.2016.07.009.

Warf, B. (2012). Global geographies of the internet. Springer Science \& Business Media.

Wood, D., Davies, S., Calapis, A., Ramsey, J., \& Dargan, P. (2012). Novel drugsnovel branding. QJM: An International Journal of Medicine, 105(11), 1125-1126. doi:10.1093/qjmed/hcr191.

Zawikska, JB. (2017). An Expanding World of Novel Psychoactive Substances: Opioids. Frontiers in Psychiatry 8:1-14. doi:10.3389/fpsyt.2017.00110. 


\section{Legislation}

Misuse of Drugs Act 1971. Retrieved from:

https://www.legislation.gov.uk/ukpga/1971/38/contents.

Psychoactive Substance Act 2016. Retrieved from

http://www.legislation.gov.uk/ukpga/2016/2/contents/enacted.

The Human Medicines Regulations 2012. Retrieved from:

http://www.legislation.gov.uk/uksi/2012/1916/contents/made. 
Table 1: Participant Demographics

\begin{tabular}{|c|c|c|c|c|c|c|c|}
\hline $\begin{array}{c}\text { Pseudony } \\
\text { m }\end{array}$ & $\underset{r}{\text { Gende }}$ & $\begin{array}{c}\mathbf{A g} \\
\mathbf{e}\end{array}$ & $\begin{array}{l}\text { At-risk } \\
\text { Young } \\
\text { Perso } \\
\text { n (YP) }\end{array}$ & $\begin{array}{c}\text { Homeles } \\
\text { s Person } \\
\text { (HP) }\end{array}$ & $\begin{array}{c}\text { Mental } \\
\text { Health } \\
\text { Service } \\
\text { User } \\
\text { (MHSU } \\
\text { ) }\end{array}$ & $\begin{array}{c}\text { Person } \\
\text { Who } \\
\text { Injects } \\
\text { Drugs } \\
\text { (PWID } \\
\text { ) }\end{array}$ & $\begin{array}{c}\text { Men } \\
\text { who } \\
\text { have } \\
\text { Sex } \\
\text { with } \\
\text { Men } \\
\text { (MSM } \\
\text { ) }\end{array}$ \\
\hline Alexander & $M$ & 42 & & & & & X \\
\hline Alistair & M & 28 & & & $x$ & & \\
\hline Andrea & $\mathrm{F}$ & 34 & & & $X$ & $\mathrm{X}$ & \\
\hline Chloe & $\mathrm{F}$ & 17 & $X$ & & & & \\
\hline Christina & $\mathrm{F}$ & 39 & & & & $X$ & \\
\hline Claire & $\mathrm{F}$ & 30 & & $X$ & $X$ & $X$ & \\
\hline Colin & $M$ & 27 & & & $X$ & & \\
\hline Daniel & $M$ & 17 & $x$ & $x$ & & $\mathrm{X}$ & \\
\hline Debbie & $\mathrm{F}$ & 22 & & $X$ & & & \\
\hline Gary & M & 39 & & $X$ & $X$ & & \\
\hline Graeme & $M$ & 44 & & & $X$ & $X$ & $X$ \\
\hline Hugh & $M$ & 61 & & & & $\mathrm{X}$ & $\mathrm{X}$ \\
\hline Jacob & $M$ & 49 & & & $X$ & & \\
\hline James & $M$ & 19 & $X$ & $X$ & & $X$ & \\
\hline Jessica & $\mathrm{F}$ & 35 & & & $\mathrm{X}$ & $\mathrm{X}$ & \\
\hline John & $M$ & 26 & & & $\mathrm{X}$ & $\mathrm{X}$ & \\
\hline Kevin & M & 35 & & & & $X$ & \\
\hline Kieran & $M$ & 46 & & & $X$ & & \\
\hline Kimberly & $\mathrm{F}$ & 32 & & & $\mathrm{X}$ & $X$ & \\
\hline Luke & M & 20 & $X$ & & & & \\
\hline Michael & $M$ & 26 & & & $X$ & & \\
\hline Michelle & $\mathrm{F}$ & 16 & $x$ & & & & \\
\hline Moira & $\mathrm{F}$ & 39 & & & & $\mathrm{X}$ & \\
\hline Nick & M & 36 & & $X$ & & & \\
\hline Nicola & $\mathrm{F}$ & 32 & & & & $\mathrm{X}$ & \\
\hline Paula & $\mathrm{F}$ & 32 & & $X$ & $X$ & & \\
\hline Peter & $M$ & 17 & $X$ & $X$ & & $X$ & \\
\hline Samuel & $M$ & 19 & $X$ & $X$ & $X$ & & \\
\hline Steven & $M$ & 39 & & $X$ & $X$ & & \\
\hline Thomas & $M$ & 45 & & & & $X$ & $X$ \\
\hline Tiffany & $\mathrm{F}$ & 28 & & & $X$ & & \\
\hline Tracey & $\mathrm{F}$ & 26 & & & $x$ & $X$ & \\
\hline William & $M$ & 55 & & & $x$ & & $\mathrm{X}$ \\
\hline Total & & & 7 & 10 & 18 & 16 & 5 \\
\hline
\end{tabular}


Table 2: Service type of focus group participants

\begin{tabular}{|l|l|}
\hline \multicolumn{1}{|c|}{ Service Type* } & \multicolumn{1}{c|}{ N } \\
\hline Drugs & 20 \\
\hline Young people & 7 \\
\hline Needle Exchange & 6 \\
\hline Mental Health & 6 \\
\hline Sexual Health & 6 \\
\hline Criminal Justice & 6 \\
\hline Housing and Homelessness & 5 \\
\hline Social Work & 4 \\
\hline
\end{tabular}

* Many participants worked in services catering to more than one area. 